\title{
CARNITINE AND GLYCERYLPHOSPHORYLCHOLINE IN THE REPRODUCTIVE TRACT OF THE MALE RAT
}

\author{
D. E. BROOKS*, D. W. HAMILTON AND ANN H. MALLEK \\ Department of Anatomy and Laboratory of Human Reproduction and Reproductive Biology, \\ Harvard Medical School, Boston, Massachusetts 02115, U.S.A.
}

(Received 29th January 1973)

\begin{abstract}
Summary. Garnitine and glycerylphosphorylcholine (GPG) levels have been measured in the reproductive tissues of male rats, with special reference to the epididymis. The increase in concentration of these compounds in reproductive tissues during the prepubertal and pubertal periods has been examined and their distribution along the epididymis has been determined in mature animals. Carnitine accumulates in the epididymal plasma in the cauda epididymidis whilst GPC accumulates in the caput epididymidis. By developing a new technique for the collection and separation of epididymal spermatozoa and undiluted fluid from the cauda epididymidis, the concentrations of carnitine, acetylcarnitine and GPC have been measured and the free fatty acid composition of epididymal plasma has also been determined and compared with blood plasma. By examining the effects of castration, testosterone replacement and cryptorchidism, the accumulation of carnitine and GPC in the epididymis has been shown to be under androgen control. By contrast, the anti-androgens, cyproterone acetate and medroxyprogesterone acetate, did not influence secretory activity, perhaps because their effect was nullified by a high androgen concentration in epididymal plasma. The antifertility compound $\alpha-$ chlorohydrin was also shown to be without effect on the concentration of carnitine and GPC in the reproductive tract. The relationship of carnitine and GPC to the metabolism of fatty acids by spermatozoa is discussed.
\end{abstract}

\section{INTRODUCTION}

Various changes take place in spermatozoa as they progress through the epididymis and it is assumed that these changes are directly related to the development by spermatozoa of the ability to fertilize an egg. One such change is the extensive alteration in their lipid composition as the spermatozoa pass along the duct (Scott, Dawson \& Rowlands, 1963; Dawson \& Scott, 1964; Grogan, Mayer \& Sikes, 1966; Pickett, Komarek, Gebauer, Benson \& Gibson, 1967; Quinn \& White, 1967; Scott, Voglmayr \& Setchell, 1967; Lavon,

\footnotetext{
* Present address: Department of Animal Physiology, Waite Agricultural Research Institute, University of Adelaide, Glen Osmond, South Australia 5064.
} 
Volcani \& Danon, 1970). The importance of these lipid changes to sperm maturation is not clear; it was suggested by Lardy \& Phillips (1941), however, that phospholipids act as substrates for mammalian sperm metabolism, and Hartree \& Mann $(1959,1961)$ demonstrated that ejaculated ram spermatozoa contain large amounts of choline plasmalogen which, in the absence of other substrates, acts as an energy source on aerobic incubation. Other work has been devoted to demonstrating that spermatozoa can synthesize lipids or incorporate fatty acids into existing lipids in vitro (Terner \& Korsh, 1962; Minassian \& Terner, 1966; Scott et al., 1967; Payne \& Masters, 1968; Mills \& Scott, 1969; Neill \& Masters, 1971, 1972), although this may not occur in vivo (Dawson, 1958).

Two compounds related to lipid metabolism, glycerylphosphorylcholine (GPC) and carnitine, are found in high concentrations in the epididymis. The former was first identified as a major constituent of semen by Dawson, Mann \& White (1957), who showed that it was present in high concentrations in the epididymal secretion in the bull and boar. Spermatozoa do not have the ability to metabolize GPC (Dawson et al., 1957), although it has been suggested that they can utilize GPC inside the female reproductive tract, owing to the presence of a diesterase (White \& Wallace, 1961; Wallace \& White, 1965). In-vivo experiments with rats suggest that epididymal GPC is formed from lecithin or choline plasmalogen (Scott, Dawson \& Rowlands, 1963) whilst in-vitro experiments with rabbits suggest that GPC is formed de novo (Wallace, Wales \& White, 1966).

Carnitine has recently been recognized as a major constituent of the epididymis (Marquis \& Fritz, 1965; Pearson \& Tubbs, 1967), although its rôle in fatty acid metabolism has been realized for some time (Fraenkel \& Friedman, 1957; Fritz, 1963). The concentration of carnitine in the epididymis seems to be the highest in the body (Marquis \& Fritz, 1965; Pearson \& Tubbs, 1967), and spermatozoa have the highest levels of the enzyme carnitine acetyltransferase (Marquis \& Fritz, 1965).

The object of the present study was to examine carefully the factors controlling the accumulation of carnitine and GPG in the epididymis with special reference to the site of accumulation and the increase in accumulation over the pubertal period. It was also our aim to examine the possibility that the breakdown of epididymal epithelial lecithin releases GPG and free fatty acids, and that carnitine is involved in the utilization of the latter by spermatozoa, whether it be for their energy requirements or for lipid synthesis. A preliminary account of this work has been reported by Brooks \& Hamilton (1973).

\section{MATERIALS AND METHODS}

\section{Animals}

Virgin male rats (strain $\mathrm{CD}$ ) of known birth date were obtained from the Charles River Breeding Laboratories, Wilmington, Ma. and were maintained on a balanced diet of Purina Laboratory Chow (Ralston Purina Co., St Louis, Mo.) with free access to water. 
Surgical procedures for castration and cryptorchidism

Animals were anaesthetized with ether and bilaterally castrated through a mid-ventral abdominal incision, leaving the epididymis intact. The testes were brought to the surface by pulling on the epididymal fat pad with serrated forceps. A single ligature was placed around the ductuli efferentes and the vascular supply to the testis. After the testes had been dissected free from the epididymides, the latter were returned to the abdominal cavity and the muscular wound and skin incision were closed.

Cryptorchidism was achieved by a rapid and effective new surgical technique which did not involve opening the abdominal cavity. Hair over each scrotum was clipped and a short incision made in the skin. The muscular coat of the scrotum was isolated by blunt dissection and freed as far as the inguinal ligament. The cauda epididymidis was identified by palpation and the gubernaculum was severed by squeezing the tip of the scrotum. When the gubernaculum was broken, the testis plus epididymis could be freely moved into the abdominal cavity. A ligature was then placed around the scrotum and pushed up as far as the inguinal ligament; after tightly tying the ligature, the scrotal musculature was excised, and the skin incision was closed. This technique effectively retained the reproductive tract entirely within the abdominal cavity.

\section{Preparation of organs for extraction}

Animals were anaesthetized by an intraperitoneal injection of Nembutal ( $80 \mathrm{mg} / \mathrm{kg}$ body $\mathrm{wt}$ ), the reproductive tracts were exposed by bilateral scrotal incisions, the epididymis from each side was dissected out and fat and connective tissue were removed by dissection with fine scissors; the same technique was used for rats with intact testes as for those which had been orchidectomized. The tissue used for extraction comprised only the epididymal tubule and its contents, the interstitium and the connective tissue capsule of the organ. For the analysis in Table 5, the epididymis was divided into various segments as shown in Pl. 1, Fig. 1: cut 1 separated the ductuli efferentes from the testis, the ductuli efferentes were isolated by cut 2 , the initial segment of the epididymis by cut 3 , the caput epididymidis by cut 4 , the cauda epididymidis by cut 5 , and the ductus deferens by cut 6 . In other instances, the epididymis was only divided into two sections by cut 4 ; the segment between cuts 1 and 4 is referred to as the caput epididymidis and that between cuts 4 and 6 as the cauda epididymidis plus ductus deferens.

In the rat, the coagulating gland lies adjacent to the seminal vesicle and shares a common peritoneal sheath. In experiments where the seminal vesicles were taken for analysis, the excised tissue contained both glands with their content of secretion.

\section{Collection of epididymal fluid}

The epididymis was obtained as described above and cleaned in the same way. Here, however, the cauda epididymidis was severed from the rest of the organ by cut $\mathrm{X}$ (Pl. 1, Fig. 1), the ductus deferens was cannulated with polyethylene tubing (o.d. 0.05 in.) and the cannula was tied securely with a cotton ligature. Under a dissecting microscope, the tubule was partially 
uncoiled by carefully teasing and cutting the surrounding connective tissue. A capillary pipette of uniform bore ('microcap' from Drummond Scientific Co., Broomall, $\mathrm{Pa}$.), the end of which had been drawn out, was then inserted into the cut end of the epididymal tubule (Pl. 2, Fig. 2). By applying a pressure of about $5 \mathrm{lb} / \mathrm{in}^{2}$. from an air cylinder, the luminal contents were gently pushed into the capillary pipette. The open end of the pipette was flame-sealed and gently centrifuged to bring the contents to the bottom (Pl. 2, Fig. 3). The drawn end of the pipette was cut off and the tube was then ready for high speed centrifugation. For this purpose, polyallomer centrifuge tubes filled with epoxy plastic (Luft, 1961) were used. Small channels in the plastic supported the pipettes in a vertical position. The tubes were then spun in a swinging bucket head at 50,000 $\mathrm{g} \max \left(1 \mathrm{hr}\right.$ at $\left.4^{\circ} \mathrm{C}\right)$. This severe centrifugation was necessary to sediment the spermatozoa through the viscous epididymal plasma. By measuring the lengths of the sperm and plasma fractions, their respective volumes could be calculated (Pl. 2, Fig. 4).

In some instances, the contents of the epididymal lumen were collected directly into Krebs-Ringer bicarbonate (DeLuca \& Cohen, 1964) from which calcium and phosphate had been omitted. Complete flushing of the epididymal tubule was achieved by filling the cannula with about $250 \mu$ l Ringer before applying the air pressure. This solution would then pass through the tubules after the epididymal contents had been flushed out.

Sperm numbers were estimated by counting in a haemocytometer.

\section{Chemicals and solvents}

Most chemicals were of analytical reagent grade and were supplied by Fisher Scientific Co., Medford, Ma. Solvents were redistilled before use. NAD ${ }^{+}$, $\mathrm{NADH}$, CoA, DL-acetylcarnitine, carnitine acetyltransferase (EG 2.3.1.7), citrate synthase (EC 4.1.3.7) and malate dehydrogenase (EC 1.1.1.37) were obtained from Boehringer Mannheim Corp., New York, N.Y. L- $\alpha$-Glycerylphosphorylcholine (cadmium chloride complex), choline iodide, 5,5'-dithiobis(2-nitrobenzoic acid), testosterone propionate, 6 $\alpha$-methyl-17 $\alpha$-hydroxyprogesterone acetate (medroxyprogesterone acetate), L-malic acid, 2-oxoglutaric acid, dithiothreitol, physostigmine sulphate and benzylpenicillin (potassium salt) were from Sigma Chemical Co., St Louis, Mo. Other chemicals were obtained as follows: L-carnitine hydrochloride from General Biochemicals, Chagrin Falls, Ohio; sodium pentobarbital (Nembutal) from Abbott Laboratories, North Chicago, Ill.; sodium heparin from Organon Inc., West Orange, N.J.; 3-chloro-1,2-propanediol ( $\alpha$-chlorohydrin) from the Upjohn Co., Kalamazoo, Mich.; 6-chloro- $\Delta 6$-1,2 $\alpha$-methylene-17 $\alpha$-hydroxyprogesterone acetate (cyproterone acetate) from Schering Corp., Bloomfield, N.J.; DL-carnitinemethyl- $\left[{ }^{14} \mathrm{C}\right]$ hydrochloride $(22.5 \mathrm{mCi} / \mathrm{mmol})$ from International Chemical and Nuclear Corp., Waltham, Ma.; free fatty acid standards from Applied Science Laboratories, Inc., State College, Pa. and Analabs, Inc., North Haven, Conn.; N-methyl-N-nitroso-p-toluenesulphonamide from Eastman Organic Chemicals, Rochester, N.Y.; and Dowex AG 50WX4 (200 to 400 mesh in the $\mathrm{H}^{+}$form) and Dowex AG $1 \mathrm{X8}$ (200 to 400 mesh in the formate form) from Bio-Rad Laboratories, Richmond, Calif. 


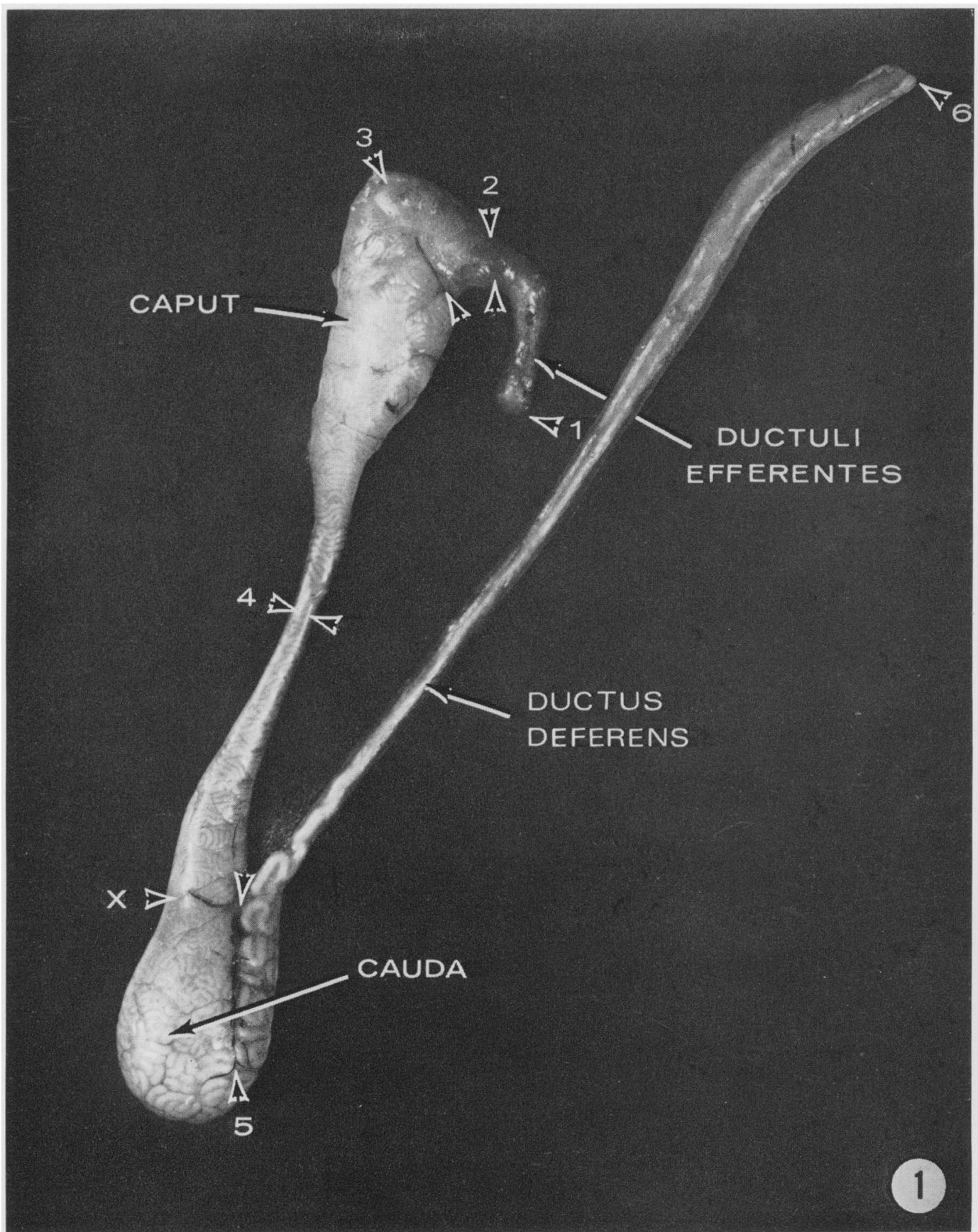

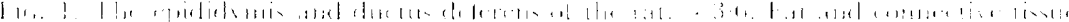

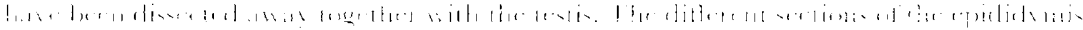

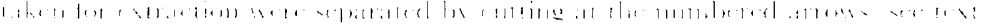




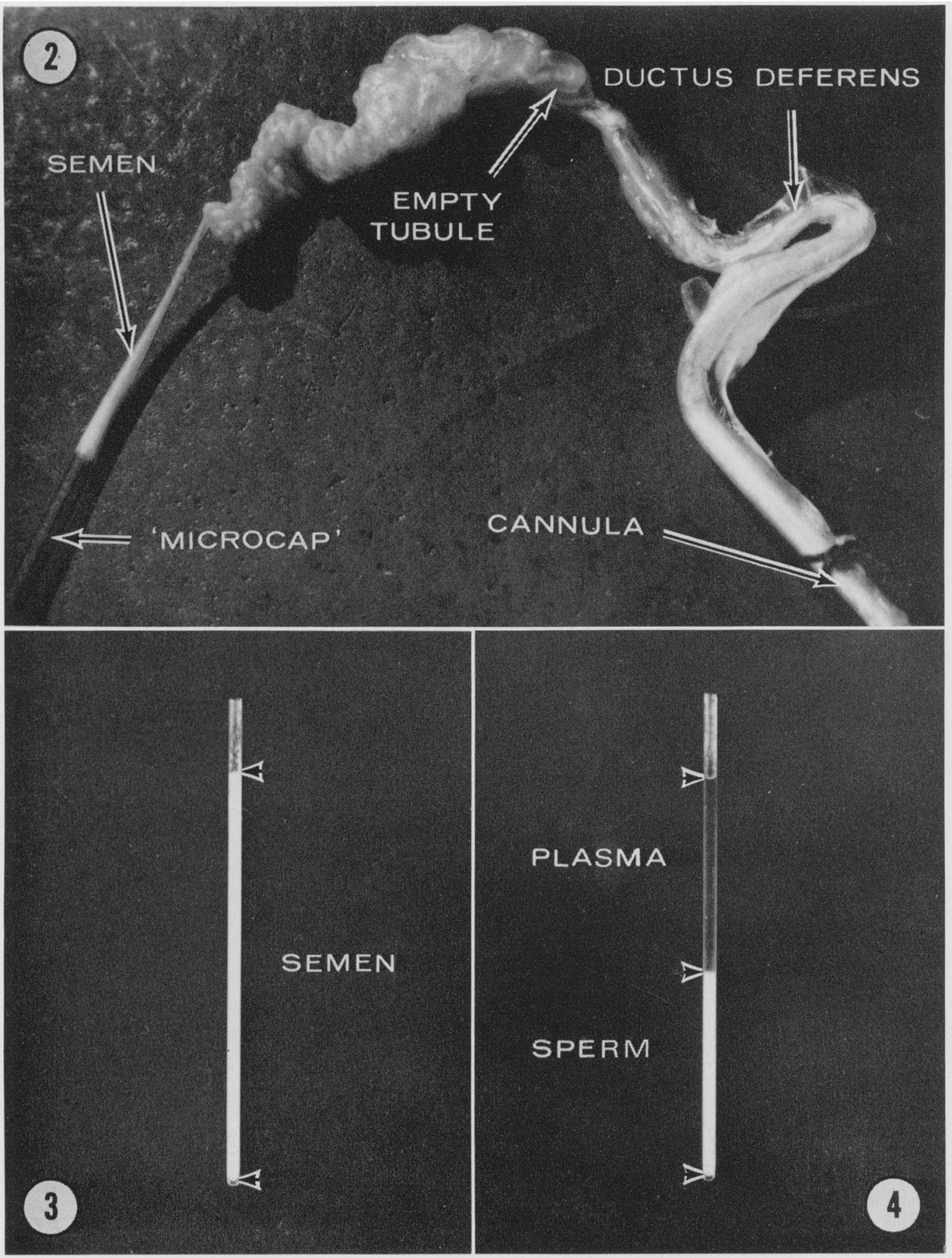

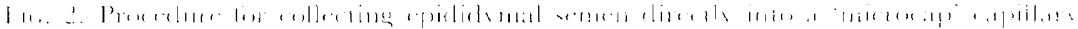

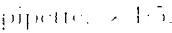

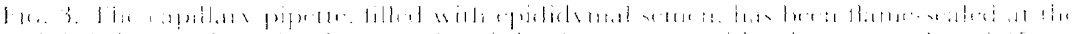

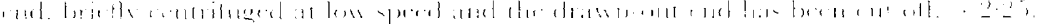

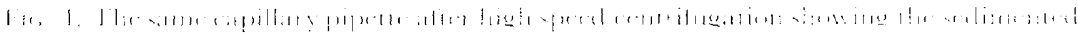

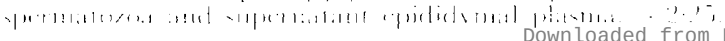


Dowex resins were washed before use as described by Brooks (1970). AcetylCoA was prepared by acetylating CoA with acetic anhydride (Stadtman, 1957). Choline acetyltransferase (EG 2.3.1.6) was prepared from beef brains by the method of Potter \& Glover (1971) and 2-oxoglutarate dehydrogenase (EC 1.2.4.2) from pig hearts as described by Sanadi, Littlefield \& Bock (1952). Milk diluent was prepared according to Harrison \& White (1972) except that $\mathrm{KCl}$ was substituted for $\mathrm{NaCl}$. Medroxyprogesterone acetate and cyproterone acetate were dissolved in corn oil by adding acetone and heating on a steam bath; excess acetone was blown off with a stream of nitrogen.

\section{Extraction procedures}

Two methods were employed for the extraction of the tissues. In the first method, the tissue was quickly weighed on a torsion balance and then extracted in a Potter-Elvehjem glass hand homogenizer with $3 \mathrm{ml}$ ice-cold $10 \%(\mathrm{w} / \mathrm{v})$ trichloroacetic acid containing $0.05 \mu \mathrm{Ci}\left[{ }^{14} \mathrm{C}\right]$ carnitine as a recovery standard. The extract was centrifuged and the supernatant shaken six times with $5 \mathrm{ml}$ ether to remove trichloroacetic acid. An aliquot of $0.1 \mathrm{ml}$ was taken for recovery determination by scintillation counting. In the second method, the procedure of Pearson \& Tubbs (1964) was followed. In this case, the tissue was first frozen in liquid nitrogen and pulverized before extraction in $3 \mathrm{ml}$ ice-cold $5 \%(\mathrm{w} / \mathrm{v})$ perchloric acid; $0.05 \mu \mathrm{Ci}$ of $\left[{ }^{14} \mathrm{C}\right]$ carnitine was also added as a recovery standard. Long chain fatty acylcarnitine was determined as the carnitine released on alkaline hydrolysis of the material insoluble in dilute perchloric acid. A comparison of the ratio of acetylcarnitine to carnitine in extracts of reproductive tissues showed no significant differences between the two extraction procedures.

\section{Assay procedures}

Spectrophotometric determination of carnitine was carried out by the method of Marquis \& Fritz (1964) in a final volume of $0.5 \mathrm{ml}$. Fluorometric assay of carnitine was carried out by a coupled reaction similar to that described by Tubbs \& Garland (1969). The final composition of the assay mixture ( $3 \mathrm{ml})$ was $0.1 \mathrm{~m}$-potassium phosphate $\mathrm{pH} 7.2,1 \mathrm{~mm}-\mathrm{MgCl}_{2}, 0.5 \mathrm{~mm}$-EDTA, 0.2 mm-dithiothreitol, $0.5 \mathrm{~mm}$-2-oxoglutarate, and $0.1 \mathrm{~mm}-\mathrm{NAD}^{+}$. One $\mu \mathrm{l}$ of $15 \mathrm{~mm}$ acetyl-CoA was added just before the addition of 2-oxoglutarate dehydrogenase. Carnitine was measured as the fluorescence increase due to the addition of carnitine acetyltransferase. The commercial preparation of carnitine acetyltransferase was found to contain glutamate dehydrogenase (EG 1.4.1.2) which caused severe interference; this was overcome by dialysing the enzyme against 20 mm-potassium phosphate $\mathrm{pH} 7 \cdot 2$ to remove ammonium sulphate.

Acetyl-CoA and acetylcarnitine were measured fluorometrically by the method described by Williamson \& Corkey (1969). The 3-ml assay volume contained $0.1 \mathrm{~m}$-potassium phosphate $\mathrm{pH} 7.2,0.033 \mathrm{~mm}$-malate, $0.1 \mathrm{~mm}-\mathrm{NAD}^{+}$, $0.05 \mathrm{~mm}$-CoA, and $0.17 \mathrm{~mm}$-EDTA. The fluorescence changes due to the successive additions of malate dehydrogenase, citrate synthase and carnitine acetyltransferase were measured and the corrections described by Pearson (1965) were applied to the results. 
The GPC was measured as choline released by acid hydrolysis under conditions in which compounds such as phosphorylcholine show negligible hydrolysis. The extract was first cleaned of charged molecules by passing it through a short column containing approximately $0.5 \mathrm{ml}$ of Dowex AG 50 on the bottom with $0.5 \mathrm{ml}$ of Dowex AG 1 layered on the top. About $10 \mathrm{ml}$ water were used to wash through the column. The extract was collected directly into a freeze-drying ampoule. After freeze-drying, the residue was taken up in $0.5 \mathrm{ml}$ water; $50 \mu \mathrm{l}$ of $10 \mathrm{M}-\mathrm{HCl}$ were added and the ampoule was heated for $20 \mathrm{~min}$ in a boiling water bath. After cooling, the sample was neutralized with $50 \mu \mathrm{l}$ of $10 \mathrm{M}-\mathrm{NaOH}$ and aliquots were then taken for choline assay.

The assay mixture consisted of the sample plus $0 \cdot 8 \mathrm{M}-\mathrm{NaCl}$ to a volume of $0.2 \mathrm{ml}$. To this was added $0.1 \mathrm{ml}$ of 0.3 M-potassium phosphate $\mathrm{pH} 7.2 \mathrm{con}$ taining $2.5 \mathrm{~mm}$-EDTA, $1 \mathrm{~mm}$-physostigmine sulphate, and $1.5 \mathrm{~mm}$-acetyl-CoA. Choline acetyltransferase preparation $(5 \mu \mathrm{l})$ was added and the tubes were incubated at $37^{\circ} \mathrm{C}$ for about $2 \mathrm{hr}$. The enzyme was precipitated by the addition of $0.2 \mathrm{ml}$ of $20 \%(\mathrm{w} / \mathrm{v})$ trichloroacetic acid followed by brief centrifugation. The CoA released during the incubation was measured by mixing $0.3 \mathrm{ml}$ of the supernatant with $0.3 \mathrm{ml}$ of $1 \mathrm{M}$-tris base and $10 \mu \mathrm{l}$ of a preparation containing $4 \mathrm{mg}$ 5,5'-dithiobis-(2-nitrobenzoic acid)/ml and recording the extinction at $412 \mathrm{~nm}$. Under the conditions used, the working range for choline estimation was 0 to $50 \mathrm{nmol}$.

\section{Other procedures}

For radioactivity counting, $0.1 \mathrm{ml}$ of the sample was added with $0.2 \mathrm{ml}$ water to $5 \mathrm{ml}$ toluene:Triton X-100 $(2: 1, \mathrm{v} / \mathrm{v})$ containing $2.67 \mathrm{~g}$ PPO and $0 \cdot 2 \mathrm{~g}$ POPOP/litre.

Free fatty acids were extracted from heparinized blood plasma and epididymal plasma by the method of Dole \& Meinertz (1960). A known amount of n-pentadecanoic acid was added as a recovery standard. The extract was dried under nitrogen and taken up in ether. Methyl esters were prepared by bubbling freshly distilled diazomethane through the etherial solution (Brooks \& Mann, 1973). Separation of the methyl esters was achieved on a $1.8 \mathrm{~m} \times 2 \mathrm{~mm}$ i.d. column of $15 \%$ diethyleneglycolsuccinate on $80 / 100$ Gas Chrom P (Applied Science Laboratories, State College, $\mathrm{Pa}$.) with a helium flow rate of $20 \mathrm{ml} / \mathrm{min}$ in a Beckman GC-45 gas chromatograph fitted with dual flame ionization detectors to balance variations in column bleed. The column was temperature programmed at $100^{\circ} \mathrm{C}$ for $40 \mathrm{~min}$ followed by a linear rise to $180^{\circ} \mathrm{C}$ in $160 \mathrm{~min}$. This gave good separation and maintained sharp peaks for esters with long retention times. Identification of the esters was achieved by comparing retention times with authentic standards and with the data of Ackman \& Burgher (1963), Haken (1966) and Hofstetter, Sen \& Holman (1965), using isothermal runs. Peak areas were estimated by cutting out and weighing the recorder tracings.

\section{Administration of $\alpha$-chlorohydrin}

After dissolving in water, $\alpha$-chlorohydrin was administered to twelve 
animals at a daily dose of $9 \mathrm{mg} / \mathrm{kg}$ body wt through a tube passed down the oesophagus; twelve other animals served as controls. The experiment was begun with 18-day-old rats which were killed at 62 days of age. Carnitine and GPG were measured in the caput epididymidis and cauda epididymidis plus ductus deferens. In addition, the concentration of GPC in the testes and seminal vesicles plus coagulating glands was also determined.

\section{RESULTS}

\section{Effect of age on the distribution of carnitine and GPC}

The increase in weight of the reproductive organs in growing animals and their content of carnitine and GPC are shown in Table 1. The ages of the rats were chosen to represent distinct stages in the attainment of full reproductive potential. At 19 days of age, primary spermatocytes were in abundance in the testis; at 36 days, many spermatids were present. It was not, however, until the completion of the first spermatogenic cycle (approximately 50 days) that spermatozoa first appeared in the epididymis. At 60 days, the animals were sexually mature, although the reproductive organs continued to increase in size after this time. In our experiments, the period from 19 to 46 days was referred to as the prepubertal period and from 46 to 60 days as the pubertal period. In general, the weight changes showed an even progression and did not show any distinct correlation with sperm movement along the epididymis.

The most notable changes which occurred during the prepubertal and pubertal periods were the large increases in weight of the reproductive organs accompanied by a large increase in the concentration of carnitine in the cauda epididymidis plus ductus deferens and of GPC in both the caput and cauda. The latter also increased greatly in the seminal vesicles plus coagulating glands. Blood levels of both compounds remained very low or undetectable during the prepubertal and pubertal periods. In the testis, the concentration of carnitine tended to decrease whilst that of GPG increased during maturation.

In the epididymis, the sites where carnitine and GPC accumulated appeared to be different. Carnitine accumulated to a much greater extent in the cauda plus ductus deferens than it did in the caput. By contrast, GPG concentrations rose more sharply in the caput and it was not until 60 days of age (when there was movement of fluid along the epididymal duct) that the concentration of this compound increased in the cauda plus ductus deferens. Carnitine levels in the seminal vesicles plus coagulating glands remained low despite large increases in GPG concentration.

\section{Distribution of carnitine and GPC in the epididymis of mature animals}

By flushing out the cauda and ductus deferens, it was possible to obtain information as to the partition of carnitine between the spermatozoa, epididymal plasma and epididymal tissue. It can be seen from Group A in Table 2 that carnitine and acetylcarnitine were present mainly in the epididymal plasma. In this experiment, the spermatozoa were washed twice and, owing to the high concentration of carnitine in the epididymal plasma, this did not seem to be adequate to rinse the spermatozoa completely. In Group B of 


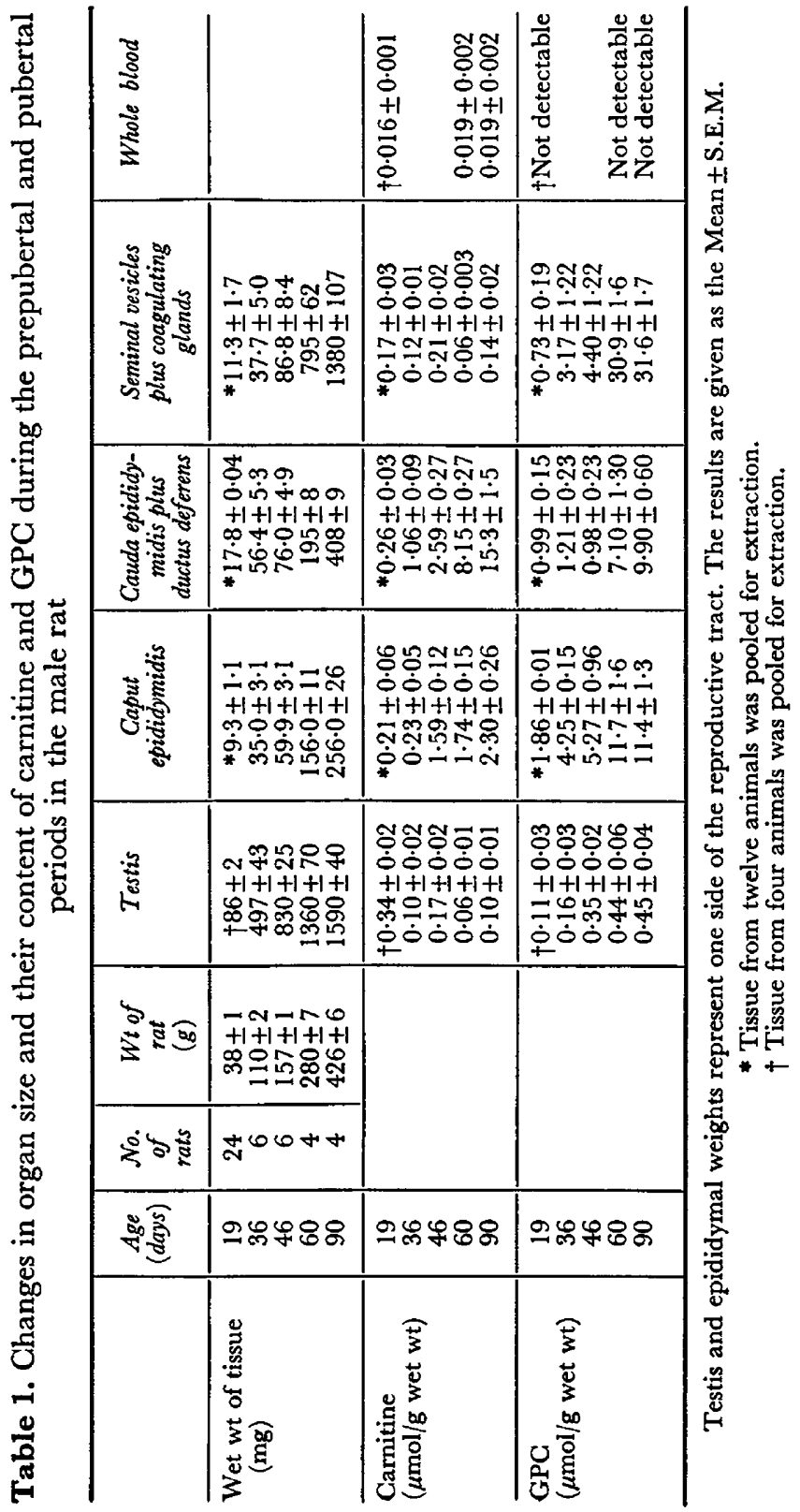


Table 2. Distribution of carnitine, acetylcarnitine and GPG between spermatozoa, epididymal plasma and the empty cauda epididymidis plus ductus deferens of rats after flushing out the epididymis with calcium- and phosphate-free Krebs-Ringer bicarbonate

\begin{tabular}{|c|c|c|c|c|c|}
\hline & \multicolumn{3}{|c|}{ Group $A$} & \multicolumn{2}{|c|}{ Group B } \\
\hline & Carnitine & Acetylcarnitine & $\begin{array}{c}\% \text { of total } \\
\text { carnitine } \\
\text { present as } \\
\text { acetylcarni- } \\
\text { tine }\end{array}$ & Carnitine & $G P C$ \\
\hline Total $\mu \mathrm{mol}$ recovered & $2 \cdot 51 \pm 0 \cdot 17$ & $0 \cdot 289 \pm 0.039$ & & $4 \cdot 58 \pm 0.51$ & $2 \cdot 25 \pm 0 \cdot 34$ \\
\hline $\begin{array}{l}\mu \mathrm{mol} / \mathrm{g} \text { wet } \mathrm{wt} \text { in } \\
\text { empty cauda epididymidis } \\
\text { plus ductus deferens }\end{array}$ & $0.483 \pm 0.019$ & $0.099 \pm 0.016$ & & $0 \cdot 805 \pm 0 \cdot 100$ & $0.350 \pm 0.068$ \\
\hline $\begin{array}{l}\% \text { recovered in } \\
\text { washed spermatozoa }\end{array}$ & $9 \cdot 6 \pm 2 \cdot 1$ & $14 \cdot 6 \pm 5 \cdot 3$ & $13 \cdot 3 \pm 3 \cdot 1$ & $0.41 \pm 0.22$ & 0 \\
\hline $\begin{array}{l}\% \text { recovered in } \\
\text { epididymal plasma }\end{array}$ & $87 \cdot 2 \pm 2 \cdot 1$ & $79 \cdot 9 \pm 5 \cdot 7$ & $9 \cdot 4 \pm 0.9$ & $94 \cdot 5 \pm 0 \cdot 1$ & $95.5 \pm 0.9$ \\
\hline $\begin{array}{l}\% \text { recovered in } \\
\text { empty cauda epididymidis } \\
\text { plus ductus deferens }\end{array}$ & $3 \cdot 2 \pm 0 \cdot 2$ & $5 \cdot 6 \pm 0 \cdot 7$ & $16 \cdot 8 \pm 2 \cdot 2$ & $5 \cdot 05 \pm 0 \cdot 24$ & $4 \cdot 5 \pm 0 \cdot 9$ \\
\hline
\end{tabular}

Four 90-day-old rats were used in each group and the results are given as the Mean + S.E.M. In Groups $A$ and $B$, the spermatozoa were separated by two and four centrifugal washings in buffer respectively.

Table 2, the spermatozoa were washed four times and the level of carnitine in the fourth wash fluid was well below that measured in the sperm extract. Carnitine and GPC were present almost exclusively in the epididymal plasma.

By collecting the epididymal contents directly into a capillary pipette and separating the spermatozoa from the plasma, it was possible to determine the molar concentrations of carnitine and GPC in epididymal plasma. Table 3 shows that spermatozoa in the cauda and ductus deferens were bathed in a fluid which contained these two compounds in very high concentrations.

The distribution of carnitine and its fatty acyl derivatives in the epididymis of mature animals is shown in Table 4, together with values for spermatozoa which had been washed carefully in milk diluent in such a way as to minimize damage to the sperm cells during the washing procedure and thereby to

Table 3. Sperm concentration, spermatocrit, carnitine and GPC concentrations in undiluted luminal contents obtained from the cauda epididymidis plus ductus deferens of rats

\begin{tabular}{l|c}
\hline $\begin{array}{l}\text { Epididymal sperm concentration } \\
\text { before centrifugation }\left(\times 10^{9} / \mathrm{ml}\right)\end{array}$ & $1.74 \pm 0.08$ \\
$\%$ packed sperm volume & $44.7 \pm 1.2$ \\
Carnitine (mM) & $63.2 \pm 3.3$ \\
GPC (mM) & $41.4 \pm 1.9$ \\
\hline
\end{tabular}

The results are given as the Mean \pm S.E.M. of twelve determinations. 
minimize leakage of cell components into the wash fluid. In both the caput and cauda epididymidis, about one tenth of the total carnitine was present as acetylcarnitine. Long-chain fatty acylcarnitine was detectable only in the cauda where its concentration was very low. There was no significant difference between the sum of carnitine plus acetylcarnitine and the total acid-soluble carnitine, indicating that acylcarnitines of chain length $\mathrm{C}_{3}$ to $\mathrm{C}_{10}$ were not present. Washed spermatozoa contained both carnitine and acetylcarnitine, but in this case the acetylcarnitine represented more than one third of the total carnitine.

Table 4. Carnitine, acetylcarnitine and long-chain fatty acylcarnitine in the epididymis and spermatozoa of rats

\begin{tabular}{l|c|c|c}
\hline & Caput epididymidis & $\begin{array}{c}\text { Cauda epididymidis } \\
\text { plus ductus deferens }\end{array}$ & Spermatozoa \\
\cline { 2 - 3 } Wet wt of tissue $(\mathrm{mg})$, or & $260 \pm 10$ & $374 \pm 7$ & $0.077 \pm 0.015$ \\
no. of sperm. extracted $\left(\times 10^{9}\right)$ & $2 \cdot 22 \pm 0.04$ & $14.6 \pm 1 \cdot 1$ & $0.620 \pm 0.208$ \\
Carnitine & $0 \cdot 247 \pm 0.009$ & $1 \cdot 19 \pm 0 \cdot 11$ & $0.354 \pm 0.092$ \\
Acetylcarnitine & Not detectable & $0 \cdot 057 \pm 0.005$ & Not detectable \\
Long-chain fatty acylcarnitine & $2 \cdot 47 \pm 0.04$ & $15.9 \pm 1 \cdot 0$ & $0.974 \pm 0.293$ \\
Total carnitine & & & \\
\hline
\end{tabular}

Five 94 -day-old rats $(433 \pm 5 \mathrm{~g})$ were used to determine values for the epididymis. Spermatozoa were flushed from the cauda epididymidis plus ductus deferens of seven other animals; these spermatozoa were washed four times in milk diluent in such a way that their motility was retained. The results are given as the Mean \pm S.E.M. and represent $\mu \mathrm{mol} / \mathrm{g}$ wet wt of epididymal tissue and $\mu \mathrm{mol} / 10^{9}$ spermatozoa. Tissue weights represent one side of the reproductive tract.

A more detailed examination of the distribution of carnitine and GPC along the excurrent duct system is presented in Table 5. The ductuli efferentes, which lead spermatozoa and fluid from the testis into the epididymis, contained very little carnitine or GPG. In the initial segment of the epididymis, the concentration of GPC had begun to rise indicating that this segment of the epididymis was involved in the accumulation of this compound. Highest concentrations of GPC were found in the caput epididymidis whilst carnitine was found in highest concentration in the cauda epididymidis. The concentrations of both compounds decreased in the ductus deferens. Neither the molar ratio of GPG to carnitine nor the proportion of total carnitine in the acetylated state were significantly different between the cauda epididymidis and the ductus deferens.

\section{Control of the accumulation of carnitine and GPC}

Prepubertal animals were castrated and allocated to two groups, one of which received testosterone replacement therapy. The reproductive organs of the control group with no testicular androgen source failed to develop and did not accumulate carnitine or GPG (Table 6). By contrast, the testosteronetreated castrates showed growth of the reproductive organs and accumulation of carnitine and GPG to a greater extent than normal animals of the same age (Table 1). 


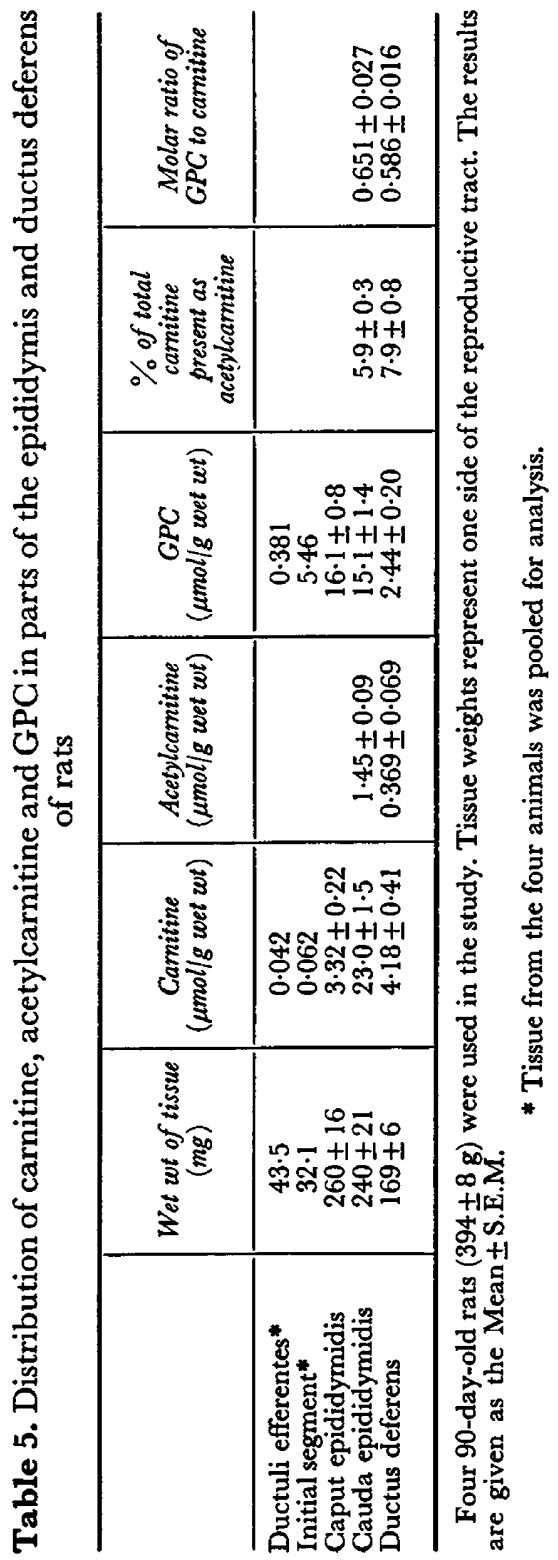


D. E. Brooks et al.

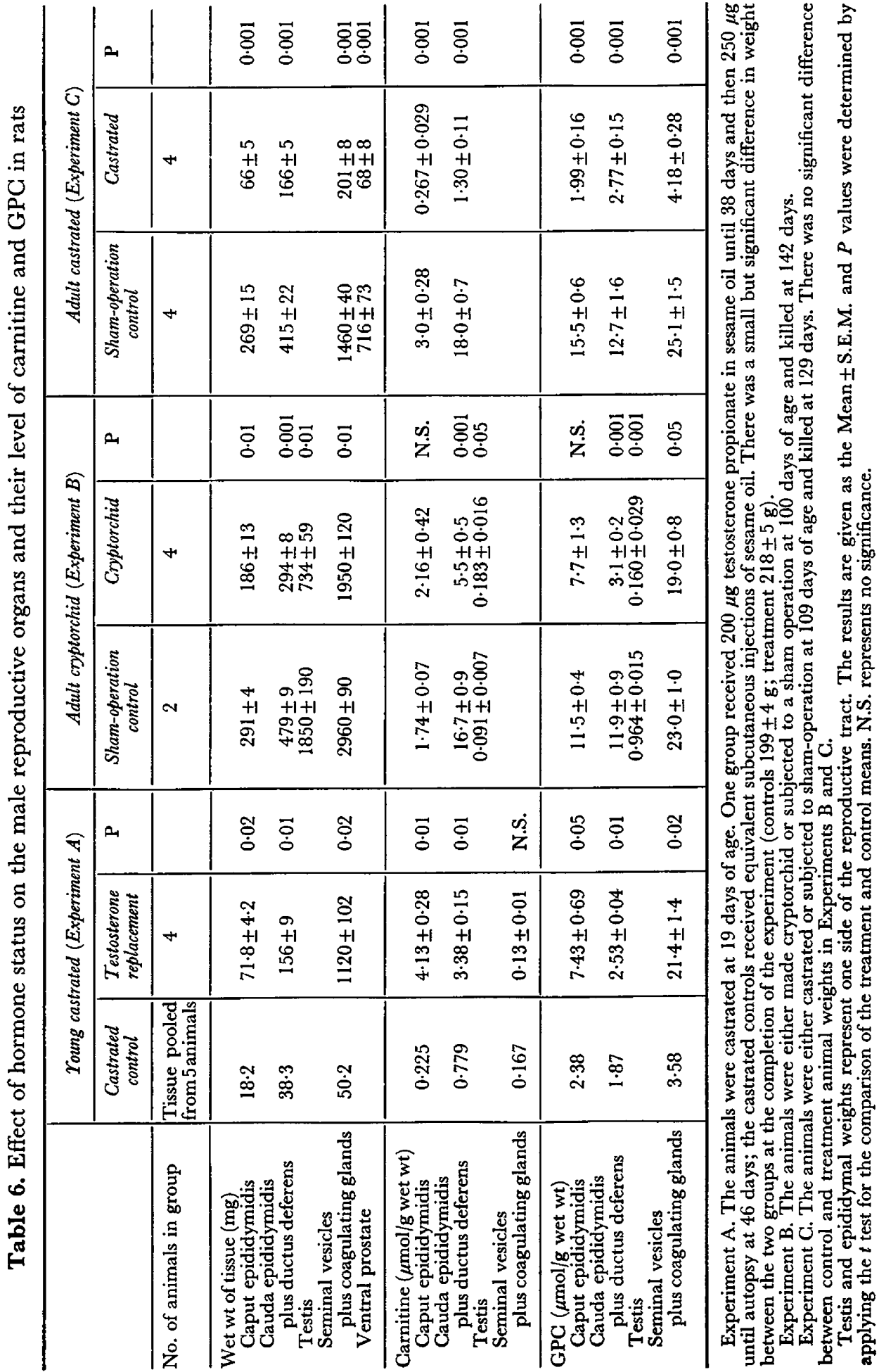




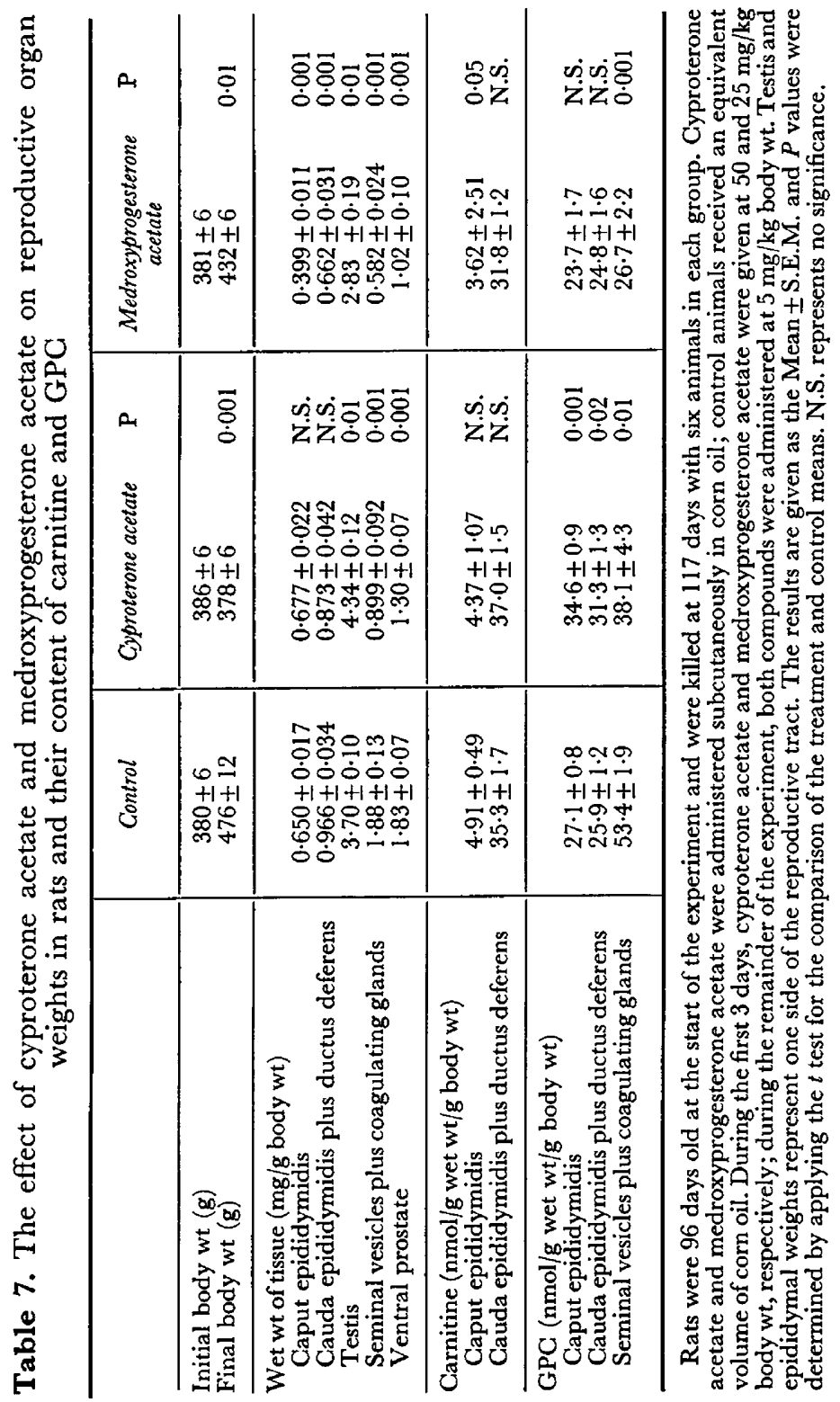


As a further test that spermatozoa do not participate in the accumulation of carnitine and GPC in the epididymis, mature animals were made cryptorchid for 6 weeks with the aim of suppressing spermatogenesis without loss of androgen production. At the time of autopsy, cessation of spermatogenesis was evident from the complete absence of spermatozoa in the epididymis. The results (Table 6) show that the epididymis had regressed as had the testis and seminal vesicles plus coagulating glands. In the testis, the concentration of GPC declined whilst that of carnitine increased. There was no significant alteration in the concentration of carnitine and GPC in the caput epididymidis although it appears that the concentration of GPC tended towards lower values than in control animals. Significant decreases in the concentration of carnitine and GPG were found, however, in the cauda epididymidis plus ductus deferens.

In contrast to the effects of reduced androgen production caused by cryptorchidism, castration of mature animals resulted in a complete cessation of androgen production. The effects on epididymal size and the concentration of carnitine and GPC were very dramatic (Table 6). These animals had been castrated for only 3 weeks but the seminal vesicles plus coagulating glands and ventral prostate had regressed almost completely. Carnitine and GPG concentrations fell to very low levels.

Two anti-androgens, cyproterone acetate and medroxyprogesterone acetate, were administered over a period of 3 weeks to adult animals to determine whether these would mimic the effects of castration. The results (Table 7) show that both compounds had a pronounced effect on the normal increase in body weight of the animals. Both compounds could be classed as having an anti-androgenic effect by the reduction in weight of the seminal vesicles plus coagulating glands and the ventral prostate. A reduction in weight of the

Table 8. Free fatty acids in blood plasma and epididymal plasma from male rats

\begin{tabular}{|c|c|c|c|c|}
\hline \multirow[b]{2}{*}{ Fatty acid } & \multicolumn{2}{|c|}{ Concentration ( $\mu$ mol/litre) } & \multicolumn{2}{|c|}{$\%$ composition by wt } \\
\hline & Blood plasma & $\begin{array}{c}\text { Epididymal } \\
\text { plasma }\end{array}$ & Blood plasma & $\begin{array}{c}\text { Epididymal } \\
\text { plasma }\end{array}$ \\
\hline 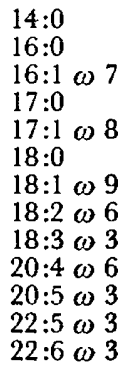 & 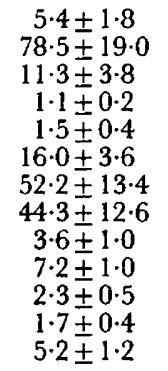 & $\begin{array}{c}27 \pm 6 \\
302 \pm 66 \\
55 \pm 8 \\
13 \pm 2 \\
19 \pm 2 \\
171 \pm 33 \\
352 \pm 98 \\
19 \pm 3\end{array}$ & $\begin{array}{r}1.8 \pm 0.2 \\
33.0 \pm 3 \cdot 6 \\
4.3 \pm 0.4 \\
0.5 \pm 0 \cdot 1 \\
0.6 \pm 0 \cdot 1 \\
6 \cdot 8 \pm 0 \cdot 2 \\
24 \cdot 2 \pm 2 \cdot 2 \\
18 \cdot 9 \pm 1 \cdot 6 \\
1.6 \pm 0 \cdot 2 \\
3.5 \pm 0 \cdot 3 \\
1.1 \pm 0 \cdot 2 \\
0.9 \pm 0.2 \\
2.8 \pm 0.4\end{array}$ & $\begin{array}{r}2 \cdot 7 \pm 0.6 \\
31 \cdot 1 \pm 4 \cdot 6 \\
6 \cdot 0 \pm 1 \cdot 0 \\
1 \cdot 7 \pm 0.4 \\
2 \cdot 3 \pm 0.5 \\
18 \cdot 8 \pm 1 \cdot 2 \\
35 \cdot 5 \pm 5 \cdot 8 \\
2 \cdot 0 \pm 0.2\end{array}$ \\
\hline Total & $230 \pm 57$ & $958 \pm 156$ & & \\
\hline
\end{tabular}

The results are given as the Mean \pm S.E.M. of nine blood plasma samples and six epididymal plasma samples. The fatty acid designation used (e.g. 16:1 $\omega$ 7) represents a sixteen carbon fatty acid with one double bond and a saturated carbon end-chain of seven units. 
epididymis, however, was noted only in animals treated with medroxyprogesterone acetate. In both treatment groups, spermatozoa were in abundance in the epididymis.

Contrary to the effects of castration, these two compounds had no effect on the concentration of carnitine in the epididymis, and either had no effect on or increased the levels of GPC in the epididymis. The levels of GPC were lower, however, in the regressed seminal vesicles plus coagulating glands.

\section{Influence of $\alpha$-chlorohydrin}

No differences between control and treated animals were found with any of the parameters that were measured.

\section{Free fatty acids in epididymal plasma and blood plasma}

By using the collecting technique developed for epididymal plasma, sufficient material was obtained to enable a determination to be made of the free fatty acid composition of epididymal plasma from individual animals. In order to make a comparison, blood plasma was also collected by decapitating unanaesthetized animals. Table 8 lists the free fatty acids identified and their respective concentrations. The composition of the free fatty acids in epididymal plasma was distinctly different from that in blood plasma; their combined concentration was also significantly higher, although this must be accepted with reservation as the plasma free fatty acid level is subject to large fluctuations during the day (Fuller \& Diller, 1970).

\section{DISCUSSION}

The results of the present study have confirmed and extended the results of Marquis \& Fritz (1965) in showing that the high levels of carnitine found in the epididymis were due to the presence of a very high concentration of carnitine in epididymal plasma from the cauda epididymidis, and that these levels were under androgenic control. In another report we have shown that carnitine is concentrated in the epididymis from the blood stream (Brooks, Hamilton \& Mallek, 1973). On the other hand, GPC seemed to be secreted principally by the caput epididymidis, in agreement with the findings of Dawson \& Rowlands (1959), Scott, Dawson \& Rowlands (1963) and Scott, Wales, Wallace \& White (1963). Amongst animals which have been studied, the presence of high levels of GPC in the seminal vesicle secretion seems to be a peculiarity of the rat and guinea-pig, and we have confirmed that the secretion of GPC by this organ is also under androgenic control (Lundquist, 1953; Williams-Ashman \& Banks, 1956; Dawson \& Rowlands, 1959). Previous determinations of GPC concentrations in plasma from the cauda epididymidis and ductus deferens in a variety of animals range from $21 \mathrm{~mm}$ to $111 \mathrm{~mm}$ (Dawson et al., 1957; Dawson \& Rowlands, 1959; White, Wallace, Wales \& Scott, 1961; Scott, Wales, Wallace \& White, 1963; Crabo, 1965; Crabo, Gustafsson, Bane, Meschaks \& Ringmar, 1967; Quinn \& White, 1967). Our values for the concentration of GPC and carnitine were $41 \mathrm{~mm}$ and $63 \mathrm{~mm}$, respectively, and indicated that these two compounds accounted for a large 
part of the total osmotic pressure of fluid from the cauda epididymidis (Levine \& Marsh (1971) found about 250 mosmol of pressure unaccounted for by the content of inorganic ions in fluid from the rat cauda epididymidis).

By treating young castrated rats with testosterone, we have been able to demonstrate normal increases in carnitine and GPG levels during the prepubertal period. Cryptorchidism in adult animals resulted in lower concentrations of carnitine and GPC in the cauda epididymidis plus ductus deferens accompanied by a reduced androgen output as shown by regression of the seminal vesicles plus coagulating glands. This may be largely a reflection of a decreased accumulation of fluid in this part of the epididymis, perhaps resulting primarily from a decreased flow of fluid along the duct from the testis and caput epididymidis. Decreases in epididymal weight and GPC concentration have been found even with unilateral cryptorchidism (Dacheux, Laporte \& Peyre, 1970), which suggests that full epididymal function can only be maintained by the presence of a high local concentration of androgen.

Androgen control of epididymal secretion could not be demonstrated by the administration of anti-androgens. It has been noticed previously that not all androgen target organs respond to cyproterone acetate (Beach \& Westbrook, 1968; Whalen \& Edwards, 1969). One explanation is that the anti-androgenic effect is dependent on the ratio of anti-androgen to androgen in the target tissue. The lack of effect of cyproterone acetate in the epididymis might therefore be due to a high local concentration of androgen, perhaps in the epididymal plasma where high concentrations have been reported (White \& Hudson, 1968).

It has been well established that $\alpha$-chlorohydrin causes sterility in the male and the effective dose rates in the rat have been well documented (Coppola, 1969; Gunn, Gould \& Anderson, 1969; Ericsson \& Baker, 1970). Although this compound has recently been shown to accumulate in the epididymis (Crabo \& Appelgren, 1972), its mechanism of action is entirely obscure. Due to the fact that $\alpha$-chlorohydrin is a competitive inhibitor of glycerol kinase (Thorner, 1972 and J. W. Thorner, personal communication), we felt that it might manifest its action by interfering with phospholipid metabolism in the epididymis and hence the secretion of GPG. Our results, however, showed that GPC and carnitine levels in the epididymis were unaffected by the administration of this compound over the prepubertal and pubertal periods.

In other tissues it has been shown that carnitine acts in a transport system whereby long-chain fatty acids can pass into the mitochondrial matrix to the site of $\beta$-oxidation. The fatty acid is first activated to form a CoA-thiol ester (Fritz \& Yue, 1964) and then forms an O-acyl ester with carnitine, catalysed by the enzyme, palmitoylcarnitine acyltransferase (Bremer, 1963; Fritz \& Yue, 1963; Norum, 1964, 1965), which has a wide specificity for acyl chain lengths from about $\mathrm{C}_{8}$ up to at least $\mathrm{C}_{18}$. Another transferase, carnitine acetyltransferase, operates with acyl chain lengths from $\mathrm{C}_{2}$ to $\mathrm{C}_{10}$ (Chase, 1967). The acylcarnitine formed is then able to penetrate through the inner mitochondrial membrane where the acyl group is released as acyl-CoA.

Although palmitoylcarnitine acyltransferase has a definite biological rôle in the oxidation of long chain fatty acids, the rôle of acetylcarnitine in 
the transport of acetyl groups out of the mitochondrion (Fritz \& Yue, 1964) has been questioned, as this process seems to be mediated principally by the formation of citrate (Srere \& Bhaduri, 1962; Lowenstein, 1965; Bressler \& Brendel, 1966). As an alternative, it has been suggested that acetylcarnitine acts as a buffer for acetyl-CoA levels (Tubbs, Pearson \& Chase, 1965; Pearson \& Tubbs, 1967). Acetate has been extracted from washed boar spermatozoa by Brooks \& Mann (1973) but its source was not identified; the present experiments demonstrated considerable amounts of acetylcarnitine in washed rat epididymal spermatozoa whilst acetyl-CoA was not detected. It therefore seems probable that acetylcarnitine in spermatozoa may be acting in an acetyl buffer system as suggested above.

The question of substrates for sperm maintenance in the epididymis has received limited attention. Contrary to the situation in ejaculated semen, reducing sugars do not seem to be available in the epididymal environment (White \& Wales, 1961). Lactic acid (6 to $11 \mathrm{~mm}$ ) and volatile fatty acids $(1.7 \mathrm{~mm}$ ) have been reported in ram epididymal plasma by Scott, Wales, Wallace \& White (1963) and Scott, White \& Annison (1961) respectively. In the present work, the concentration of long-chain free fatty acids in rat epididymal plasma has been measured as $1 \mathrm{~mm}$. All of these determinations are subject to the criticism that they were made on fluid which took a considerable period of time to isolate and therefore the concentrations may not represent the situation in vivo. The presence of these compounds in epididymal plasma collected in this way can, however, be taken as a good indication that they are normally available to the spermatozoa in the epididymis.

The results in Tables 2, 4 and 5 indicate that between 5 and $10 \%$ of the carnitine in epididymal plasma is present as acetylcarnitine. Taking the figure of $63 \mathrm{~mm}$ for the carnitine concentration in epididymal plasma, the concentration of acetylcarnitine can be calculated as 3 to $6 \mathrm{~mm}$. Long chain acylcarnitine levels appear to be quite low $(0.4 \%$ of the total carnitine).

The presence of significant amounts of free fatty acids, carnitine and acetylcarnitine in epididymal plasma suggests that these fatty acids may be oxidized in the epididymis. The presence of large quantities of GPC and the differing free fatty acid composition in comparison with blood plasma imply that lecithin in the epididymal epithelium is the source of these fatty acids, although the loss in sperm lipid which occurs during epididymal transit must also contribute. Although spermatozoa possess high levels of carnitine acetyltransferase (Marquis \& Fritz, 1965), their palmitoylcarnitine acyltransferase activity is not known, but they must presumably have this enzyme in order to oxidize free fatty acids as measured by Hartree \& Mann $(1959,1961)$. The extracellular location of large amounts of acetylcarnitine may represent a translocation function for this compound in addition to the buffering action mentioned previously, and it is possible that some of these acetyl groups are used for the synthesis of sperm choline plasmalogen that has been suggested to occur during epididymal transit (Scott, Dawson \& Rowlands, 1963; Dawson \& Scott, 1964).

It might be questioned whether the excessive amounts of carnitine and GPC in epididymal plasma have any biological significance. The high levels of GPC 
may merely reflect a by-product of the fatty acid requirement for metabolism of the sperm population during their epididymal transit if GPC is derived from lecithin breakdown. On the other hand, carnitine is probably of great importance to the continued metabolism of the spermatozoa on ejaculation. Since the epididymal contents are diluted with accessory gland secretions on ejaculation, a high concentration of carnitine in epididymal plasma would ensure an adequate concentration of this compound for the ejaculated spermatozoa.

\section{ACKNOWLEDGMENTS}

One of us (D.E.B.) is in receipt of a Ford Foundation Fellowship and D.W.H. is an N.I.H. Career Development Awardee. Financial support from The Population Council and grant HD-04290 from the N.I.H. are also gratefully acknowledged. Photographic work was kindly carried out by Mr A. Ley.

\section{REFERENCES}

Ackman, R. G. \& Burgher, R. D. (1963) A proposed basis for the systematic identification of unsaturated fatty acid esters through gas-liquid chromatography on polyester substrates. $\mathcal{F}$. Chromat. 11, 185.

BEACH, F. A. \& WESTBROoK, W. H. (1968) Morphological and behavioural effects of an 'antiandrogen' in male rats. $\mathcal{F}$. Endocr. $42,379$.

BREMRR, J. (1963) Carnitine in intermediary metabolism. The biosynthesis of palmitylcarnitine by cell subfractions. F. biol. Chem. 238, 2774.

BREssler, R. \& BRENDEL, K. (1966) The role of carnitine and carnitine acyltransferase in biological acetylations and fatty acid synthesis. 7 . biol. Chem. 241, 4092.

BRooks, D. E. (1970) Acid-soluble phosphorus compounds in mammalian semen. Biochem. 7. 118, 851.

BRooks, D. E. \& Hamilton, D. W. (1973) Carnitine and glycerylphosphorylcholine in the rat epididymis. Fedn Proc. Fedn Am. Socs exp. Biol. 32, 309.

Brooks, D. E., Hamilton, D. W. \& MALLEK, A. H. (1973) The uptake of L-[methyl- $\left.{ }^{3} \mathrm{H}\right]$ carnitine by the rat epididymis. Biochem. biophys. Res. Commun. 52, 1354.

Brooks, D. E. \& ManN, T. (1973) Pyruvate metabolism in boar spermatozoa. F. Reprod. Fert. 34, 105.

Cilase, J. F. A. (1967) The substrate specificity of carnitine acetyltransferase. Biochem. J. 104, 510.

Coppola, J. A. (1969) An extragonadal male antifertility agent. Life Sciences, 8, I, 43.

Crabo, B. (1965) Studies on the composition of epididymal content in bulls and boars. Acta vet. scand. 6, Suppl. 5.

CRAbo, B. \& Appelgren, L.-E. (1972) Distribution of $\left[{ }^{14} \mathrm{C}\right] \alpha$-chlorohydrin in mice and rats. 7. Reprod. Fert. 30, 161 .

Grabo, B., Gustafsson, B., Bane, A., Meschaks, P. \& Ringmar, J. E. (1967) The concentration of sodium, potassium, calcium, inorganic phosphate, protein and glycerylphosphorylcholine in the epididymal plasma of bull calves. $\mathcal{7}$. Reprod. Fert. 13, 589 .

Dacheux, J. L., Laporte, P. \& Peyre, A. (1970) Mise en évidence de corrélations testiculo-épididymaires d'après les variations de la glycérylphosphorylcholine. I. Etude lors d'une cryptorchidie unilatérale. C. r. Séanc. Soc. Biol. 164, 2074.

Dawson, R. M. G. (1958) The labelling of ram semen in vivo with radioactive phosphate and [carboxy- $\left.{ }^{14} \mathrm{C}\right]$ stearic acid. Biochem. F. 68, 512.

Dawson, R. M. G., MANN, T. \& WHITE, I. G. (1957) Glycerylphosphorylcholine and phosphorylcholine in semen, and their relation to choline. Biochem. F. 65, 627 .

Dawson, R. M. C. \& Rowlands, I. W. (1959) Glycerylphosphorylcholine in the male reproductive organs of rats and guinea-pigs. Q. 7 l exp. Physiol. 44, 26.

Dawson, R. M. G. \& Scott, T. W. (1964) Phospholipid composition of epididymal spermatozoa prepared by density gradient centrifugation. Nature, Lond. 202, 292.

DeLuca, H. F. \& Cohen, P. P. (1964) Suspending media for animal tissues. In: Manometric Techniques, 4th edn, p. 131. Eds. W. W. Umbreit, R. H. Burris and J. F. Stauffer. Burgess Publishing Go., Minnesota.

Dole, V. P. \& MeInertz, H. (1960) Microdetermination of long-chain fatty acids in plasma and tissues. 7. biol. Chem. 235, 2595.

ERICsson, R. J. \& BAKER, V. F. (1970) Male antifertility compounds: biological properties of U-5897 and U-15,646. F. Reprod. Fert. 21, 267. 
Fraenkel, G. \& Friedman, S. (1957) Garnitine. Vitams Horm. 15, 73.

FrITz, I. B. (1963) Carnitine and its role in fatty acid metabolism. Adv. Lipid Res. 1, 285.

FRITz, I. B. \& YUE, K. T. N. (1963) Long-chain carnitine acyltransferase and the role of acylcarnitine derivatives in the catalytic increase of fatty acid oxidation induced by carnitine. F. Lipid Res. 4, 279.

FRITZ, I. B. \& Yue, K. T. N. (1964) Effects of carnitine on acetyl-CoA oxidation by heart muscle mitochondria. Am. F. Physiol. 206, 531.

Fuller, R. W. \& Diller, E. R. (1970) Diurnal variation of liver glycogen and plasma free fatty acids in rats fed ad libitum or single daily meal. Metabolism, 19, 226.

Grogan, D. E., Mayer, D. T. \& Sikes, J. D. (1966) Quantitative differences in phospholipids of ejaculated spermatozoa and spermatozoa from three levels of the epididymis of the boar. $\mathcal{F}$. Reprod. Fert. 12, 431.

Gunn, S. A., Gould, T. G. \& Anderson, W. A. D. (1969) Possible mechanism of post-testicular antifertility action of 3-chloro-1,2-propanediol. Proc. Soc. exp. Biol. Med. 132, 656.

HAKEN, J. K. (1966) Retention time relationships in the gas chromatography of the methyl esters of fatty acids. F. Chromat. 23, 375.

HARRison, R. A. P. \& White, I. G. (1972) Some methods for washing spermatozoa from bull, boar and ram: a comparison using biochemical and other criteria. F. Reprod. Fert. 29, 271.

Hartree, E. F. \& ManN, T. (1959) Plasmalogen in ram semen, and its role in sperm metabolism. Biochem. 7. 71, 423.

Hartree, E. F. \& MANN, T. (1961) Phospholipids in ram semen: metabolism of plasmalogen and fatty acids. Biochem. 7. 80, 464 .

Hofstetter, H. H., Sen, N. \& Holman, R. T. (1965) Characterization of unsaturated fatty acids by gas-liquid chromatography. F. Am. Oil Chem. Soc. 42, 537.

Lardy, H. A. \& Phillips, P. H. (1941) The interrelation of oxidative and glycolytic processes as sources of energy for bull spermatozoa. Am. F. Physiol. 133, 602 .

Lavon, U., Volcani, R. \& Danon, D. (1970) The lipid content of bovine spermatozoa during maturation and ageing. 7. Reprod. Fert. 23, 215.

Levine, M. \& MARSh, D. J. (1971) Micropuncture studies of the electrochemical aspects of fluid and electrolyte transport in individual seminiferous tubules, the epididymis and the vas deferens in rats. F. Physiol., Lond. 213, 557.

LOWENSTEIN, J. M. (1965) A comparison of acetyl group utilization from various precursors. In: Recent Research on Carnitine, p. 97. Ed. G. Wolf. Massachusetts Institute of Technology Press, Cambridge, Mass.

LUFT, J. H. (1961) Improvements in epoxy resin embedding methods. F. biophys. biochem. Cytol. 9, 409.

LUNDQUisT, F. (1953) Glycerophosphoryl choline as a precursor of free choline in mammalian semen. Nature, Lond. 172, 587.

Marquis, N. R. \& FrTtz, I. B. (1964) Enzymological determination of free carnitine concentrations in rat tissues. F. Lipid Res. 5, 184.

Marquis, N. R. \& FrITZ, I. B. (1965) Effects of testosterone on the distribution of carnitine, acetylcarnitine, and carnitine acetyltransferase in tissues of the reproductive system of the male rat. 7. biol. Chem. 240, 2197.

MilLs, S. G. \& ScotT, T. W. (1969) Metabolism of fatty acids by testicular and ejaculated ram spermatozoa. F. Reprod. Fert. 18, 367.

Minasslan, E. S. \& TERner, G. (1966) Biosynthesis of lipids by human and fish spermatozoa. Am. $\mathcal{J}$. Physiol. 210, 615.

Neill, A. R. \& Masters, C. J. (1971) Incorporation of [U- $\left.{ }^{14} \mathrm{C}\right]$ palmitic acid into the phospholipids of bovine semen. 7. Reprod. Fert. 24, 295.

Neill, A. R. \& Masters, G. J. (1972) Metabolism of fatty acids by bovine spermatozoa. Biochem. $\mathcal{F}$. $127,375$.

Norum, K. R. (1964) Palmityl-CoA: carnitine palmityltransferase. Purification from calf-liver mitochondria and some properties of the enzyme. Biochim. biophys. Acta, 89, 95.

Norum, K. R. (1965) Palmityl-GoA: carnitine palmityltransferase. Studies on the substrate specificity of the enzyme. Biochim. biophys. Acta, 99, 511 .

PAYNe, E. \& MASTERS, G. J. (1968) Incorporation of ${ }^{14} \mathrm{G}$-labelled fatty acids into the lipids of bovine spermatozoa. Life Sciences, 7, II, 935.

Pearson, D. J. (1965) A source of error in the assay of acetyl-coenzyme A. Biochem. 7. 95, 23c.

Pearson, D. J. \& TubBs, P. K. (1964) Tissue levels of acid-insoluble carnitine in rat heart. Biochim. biophys. Acta, 84, 772 .

Pearson, D. J. \& Tubrs, P. K. (1967) Carnitine and derivatives in rat tissues. Biochem. F. 105, 953.

Pickett, B. W., Komarek, R. J., Gebauer, M. R., Benson, R. W. \& Grbson, E. W. (1967) Lipid and dry weight of ejaculated, epididymal and post-castrate semen from boars. F. Anim. Sci. 26, 792. 
Potter, L. T. \& Glover, V. A. S. (1971) Choline acetyltransferase (mammalian brain). In: Methods in Enzymology, Vol. 17B, p. 798. Eds. H. Tabor and C. W. Tabor. Academic Press, New York.

Quins, P.J. \& White, I. G. (1967) Phospholipid and cholesterol content of epididymal and ejaculated ram spermatozoa and seminal plasma in relation to cold shock. Aust. J. biol. Sci. 20, 1205.

Sanadi, D. R., Littlefield, J. W. \& Bock, R. M. (1952) Studies on $\alpha$-ketoglutaric oxidase. II. Purification and properties. 7. biol. Chem. 197, 851 .

Scotr, T. W., Dawson, R. M. G. \& Rowlands, I. W. (1963) Phospholipid interrelationships in rat epididymal tissue and spermatozoa. Biochem. 7. 87, 507.

Scott, T. W., Voglmayr, J. K. \& Serchell, B. P. (1967) Lipid composition and metabolism in testicular and ejaculated ram spermatozoa. Biochem. $7.102,456$.

ScotT, T. W., Wales, R. G., Wallace, J. C. \& Whrte, I. G. (1963) Composition of ram epididymal and testicular fluid and the biosynthesis of glycerylphosphorylcholine by the rabbit epididymis. 7. Reprod. Fert. 6, 49 .

Scott, T. W., White, I. G. \& Annison, E. F. (1961) Fatty acids in semen. Biochem. 7. 78, 740.

Srere, P. A. \& Bhaduri, A. (1962) Incorporation of radioactive citrate into fatty acids. Biochim. biophys. Acta, 59, 487.

Stadtman, E. R. (1957) Preparation and assay of acyl coenzyme $A$ and other thiol esters; use of hydroxylamine. In: Methods in Enzymology, Vol. 3, p. 931. Eds. S. P. Colowick and N. O. Kaplan. Academic Press, New York.

Terner, C. \& Korsh, G. (1962) The biosynthesis of ${ }^{14}$ G-labeled lipids by isolated bull spermatozoa. Biochemistry, Washington, $1,367$.

Thorner, J. W. (1972) The molecular properties of glycerol kinase from Escherichia coli. Ph.D. thesis, Harvard University.

Tubbs, P. K. \& Garland, P. B. (1969) Assay of coenzyme $A$ and some acyl derivatives. In: Methods in Enzymology, Vol. 13, p. 535. Ed. J. M. Lowenstein. Academic Press, New York.

Tubbs, P. K., Pearson, D. J. \& Chase, J. F. A. (1965) Assay of carnitine and coenzyme $A$ and their derivatives in tissues. In: Recent Research on Carnitine, p. 117. Ed. G. Wolf. Massachusetts Institute of Technology Press, Cambridge, Mass.

Wallace, J. G., Wales, R. G. \& White, I. G. (1966) The respiration of the rabbit epididymis and its synthesis of glycerylphosphorylcholine. Aust. F. biol. Sci. 19, 849.

Wallace, J. G. \& White, I. G. (1965) Studies of glycerylphosphorylcholine diesterase in the female reproductive tract. $\mathcal{7}$. Reprod. Fert. $9,163$.

Whalen, R. E. \& EDwards, D. A. (1969) Effects of the anti-androgen cyproterone acetate on mating behavior and seminal vesicle tissue in male rats. Endocrinology, 84, 155.

Whrre, I. G. \& Hudson, B. (1968) The testosterone and dehydroepiandrosterone concentration in fluids of the mammalian male reproductive tract. F. Endocr. 41, 291.

White, I. G. \& Wales, R. G. (1961) Comparison of epididymal and ejaculated semen of the ram. $\mathcal{F}$. Reprod. Fert. 2, 225.

White, I. G. \& WAllace, J. G. (1961) Breakdown of seminal glycerylphosphorylcholine by secretions of the female reproductive tract. Nature, Lond. $189,843$.

Whrte, I. G., Wallace, J. G., Wales, R. G. \& Scotr, T. W. (1961) The occurrence and metabolism of glycerylphosphorylcholine in semen and the genital tract. Proc. 4th Int. Cong. Anim. Reprod., The Hague, 2, 266.

Williams-Ashman, H. G. \& Banks, J. (1956) Participation of cytidine coenzymes in the metabolism of choline by seminal vesicle. 7 . biol. Chem. 223, 509.

Williamson, J. R. \& CoRKey, B. E. (1969) Assays of intermediates of the citric acid cycle and related compounds by fuorometric en zyme methods. In: Methods in Enzymology, Vol. 13, p. 434. Ed. J. M. Lowenstein. Academic Press, New York. 